\title{
Clinical efficacy and safety of maintenance therapy for advanced non-small cell lung cancer: a retrospective real-world study
}

Xiangwei $\mathrm{Xu}^{1 \dagger}$, Ruya Li ${ }^{2 \dagger}$, Peizhen Zhu ${ }^{3}$, Penghai Zhang ${ }^{3}$, Jun Chen ${ }^{1}$, Yongsheng Lin ${ }^{3}$ and Yinqiao Chen ${ }^{3^{*}}$

\begin{abstract}
Background: The clinical efficacy and safety of maintenance therapy (MT) for patients with advanced non-small cell lung cancer (NSCLC) have not been determined in the real word. This retrospective study of real-world data analyzed these issues in patients with advanced NSCLC and stable or responsive tumors after 4-6 cycles of first-line chemotherapy.
\end{abstract}

Methods: We classified 158 patients into MT (34 IIIB and 37 IV stage) and non-MT (47 IIIB and 40 IV stage) groups and then compared the clinical outcomes of progression-free survival (PFS) and overall survival (OS). The influences of maintaining chemotherapy or targeted drugs, regimens, and duration on PFS were also investigated. Prognostic factors for OS were identified by univariate and multivariate analyses.

Results: Among the patients, 71 received MT and 87 did not. The median PFS and OS were significantly prolonged in the MT group than non-MT group (5.6 and 14.2 vs. 2.8 and 9.8 months, respectively; both $p<0.0001$ ). The PFS was extended when patients were maintained with targeted drugs compared with chemotherapy, $>4$ cycles of chemotherapy, and targeted drugs for $>3$ months (all $P<0.0001$ ). Patients with adenocarcinoma and without distant metastasis derived a better OS benefit from MT ( $P=0.041$ and $P=0.037$, respectively). Multivariate analysis revealed that female sex and MT were independent prognostic factors for extended OS ( $P=0.039$ and $P<0.0001$, respectively). The major adverse events of MT comprised tolerable hematological toxicity and gastrointestinal reactions.

Conclusions: MT was advantageous and tolerable for patients with advanced NSCLC, especially those with adenocarcinomas without distant metastasis who were treated with targeted drugs, which was an independent prognostic factor for OS.

\section{Highlights}

1. Maintenance therapy extended PFS and OS of patients with NSCLC.

2. MT with targeted drugs significantly improved PFS compared with chemotherapy.

3. Longer duration of MT with chemotherapy or targeted drugs prolonged PFS.

\footnotetext{
*Correspondence: chenyinqiao668@163.com

${ }^{\dagger}$ Xiangwei Xu and Ruya Li should be regarded as co-first authors.

${ }^{3}$ Department of Medical Oncology, The First People's Hospital

of Yongkang, No. 599 jinshan West Road, dongcheng Street,

Yongkang 321300, Zhejiang, China

Full list of author information is available at the end of the article
}

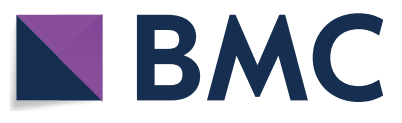

(c) The Author(s) 2021. Open Access This article is licensed under a Creative Commons Attribution 4.0 International License, which permits use, sharing, adaptation, distribution and reproduction in any medium or format, as long as you give appropriate credit to the original author(s) and the source, provide a link to the Creative Commons licence, and indicate if changes were made. The images or other third party material in this article are included in the article's Creative Commons licence, unless indicated otherwise in a credit line to the material. If material is not included in the article's Creative Commons licence and your intended use is not permitted by statutory regulation or exceeds the permitted use, you will need to obtain permission directly from the copyright holder. To view a copy of this licence, visit http://creativecommons.org/licenses/by/4.0/. The Creative Commons Public Domain Dedication waiver (http://creativeco mmons.org/publicdomain/zero/1.0/) applies to the data made available in this article, unless otherwise stated in a credit line to the data. 
4. Patients with adenocarcinomas and NSCLC without distant metastasis gained more OS benefits from MT.

5. Female sex and MT were independent prognostic factors for extended OS.

6. Patients with NSCLC tolerated MT without serious adverse events.

Keywords: Advanced non-small cell lung cancer, Maintenance therapy, Chemotherapy, Targeted drug, Prognosis, Survival

\section{Background}

Lung cancer remains the leading global cause of cancerrelated deaths $[1,2]$, accounting for $\sim 1.6$ million annually [3]. Non-small cell lung cancer (NSCLC) accounts for $85 \%$ of all lung cancers and it histologically comprises adenocarcinoma, squamous cell carcinoma, large cell carcinoma, and other subtypes [4]. Despite significant recent progress, NSCLC is often diagnosed at advanced stages when treatment options are limited. The dawn of immune checkpoint inhibitors has notably improved the therapeutic landscape of NSCLC in terms of prolonging the life spans of patients, but real-life data remain scarce [5].

Four to six cycles of platinum-based chemotherapy are the standard first-line therapy. Patients with pStage IBIIIA NSCLC can tolerate effective adjuvant chemotherapy with carboplatin and emcitabine well [6]. However, the prognosis for patients with advanced NSCLC is disappointing, as the 5 -year overall survival (OS) rate is $<5 \%$ [7]. A meta-analysis has shown that recombinant human endostatin together with chemotherapy is safe and effective for treating advanced squamous cell lung cancer [8]. Although adding preoperative radiotherapy to chemotherapy increases the pathological response and mediastinal downstaging, it does not improve the long-term survival of patients with resectable stage IIIA/N2 NSCLC [9].

Novel therapeutic methods are urgently needed to improve the progression-free survival (PFS) and OS of these patients. At least two clinical trials have found that maintenance therapy (MT) confers survival benefits on patients with NSCLC $[10,11]$. Switch and continuous MT strategies are defined as continuing drugs administered during first-line therapy, or adding drugs that differ from first-line therapy [12]. Evidence-based medicine has shown that MT with one agent can prolong the interval before advanced NSCLC progresses and results in death [13-15]. For example, continuous pemetrexed has been suggested for patients with adenocarcinomas of NSCLC, and gemcitabine is recommended for patients with squamous NSCLC [16]. Doublet MT with various treatment regimens has also been suggested, but consensus has not yet been reached [17]. Indeed, several types of MT might not be appropriate for all patients with NSCLC, such as those with inadequate organ function to tolerate the extra toxicity of MT, and some adverse events might accelerate tumor progression $[18,19]$. Economic factors are also an important reason for the refusal of patients to undergo MT, and these are usually insufficiently considered in controlled clinical trials [20]. Therefore, elucidating the real-world reliability and necessity of MT for patients with advanced NSCLC is clinically meaningful.

Considering medical insurance payments and concomitant therapies, we retrospectively evaluated the clinical effects and adverse reactions of MT in patients with stage IIIB/IV NSCLC at our hospital to provide a more comprehensive understanding of the value of MT for patients with advanced NSCLC. We also compared clinical outcomes between switching with targeted drugs and continuous chemotherapy with different regimens and durations in a subgroup analysis. We then identified a subgroup of patients who might derive more benefits from MT, based on a confirmed pathological type of NSCLC and smoking history.

\section{Materials and methods Patient enrollment}

This retrospective study collected clinical data from consecutive patients with stable or responding stage IIIB/IV NSCLC who received 4-6 cycles of first-line platinumbased chemotherapy between January 2013 and June 2019 at Yongkang First People's Hospital. The inclusion criteria were as follows: age 18-80 years; histologically or cytologically confirmed stage IIIB/IV NSCLC according to the TNM classification of the Union for International Cancer Control (UICC) (8th edition) [21]; complete response $(\mathrm{CR})$, partial response $(\mathrm{PR})$, or stable disease (SD) after 4-6 cycles of first-line platinum-based chemotherapy, according to Evaluation Criteria in Solid Tumors (RECIST Version 1.1) [22, 23]; with or without MT after first-line chemotherapy; no other second- or third-line treatments after disease progression; no radiotherapy, immunotherapy, or other therapies before MT; no serious cardiac disease or other concomitant; and complete clinical data. Exclusion criteria comprised failure to complete 4-6 cycles of chemotherapy, progressive disease (PD) after chemotherapy, other treatments after disease progression, severe cardiac diseases, liver or kidney 
dysfunction, or infectious diseases and undergoing concurrent radiotherapy. All enrolled patients provided written, informed consent to participate in this study, which was approved by the Clinical Medical Ethics Committee of Yongkang First People's Hospital (Approval code: ykyy2018-04).

\section{Study design}

Clinical data included sex, age, marital status, smoking status, type of medical insurance, pathological type, clinical stage, metastatic sites, distal metastasis, performance status (PS) score, first-line chemotherapy drugs, antiangiogenic drugs, therapeutic effects evaluated after first-line chemotherapy, MT regimen (targeted and antiangiogenic drugs, chemotherapy with one drug), complications during chemotherapy, and follow-up information. Patients with stable or responsive stage IIIB/IV NSCLC were also classified into the MT and non-MT groups according to whether they received MT or not after 4-6 cycles of first-line chemotherapy.

By reviewing the hospital clinical records, as well as messages and telephone follow-up, tumor response and complications were analyzed until the end of December 31, 2019. The endpoints comprised the PFS calculated from the first dose until disease progression, and OS calculated from the initial diagnosis to death or the end of follow-up, which are expressed on a monthly basis.

\section{Efficacy assessment}

According to RECIST1.1, tumor responses compared with baseline were evaluated as CR (complete disappearance of all target and non-target lesions, with no development of new disease), PR ( $\geq 30 \%$ decrease in the sum of the diameters of target lesions), $\mathrm{PD}(\geq 20 \%$ increase in the sum of target lesions with an absolute increase of $>5 \mathrm{~mm}$, or the appearance of at least one new lesion), and SD (shrinkage insufficient to qualify as PR or increase insufficient to qualify as PD).

\section{Safety assessment}

All complications that developed in this study were evaluated using Common Terminology Criteria Adverse Events Version 5.0 (https://ctep.cancer.gov/protocolde velopment/electronic_applications/docs/ctcae_v5_ quick_reference_5x7.pdf), and classified as grades 1-5. The major adverse events included leukopenia, neutropenia, thrombocytopenia, anemia, nausea, vomiting, diarrhea, neurotoxicity, transaminase elevation, renal toxicity, weakness, rash, myalgia, and arrhythmia.

\section{Statistical analysis}

Data were analyzed and figures were drafted using Excel (Microsoft Corp., Redmond, WA, USA), SPSS 17.0, (SPSS
Inc., Chicago, IL, USA), and GraphPad Prism 5.0 (GraphPad Software, San Diego, CA, USA). Descriptive statistics were used for qualitative data and compared using twosided chi-square tests. Quantitative data are expressed as means \pm standard deviation and were compared using two-sided independent t-tests. Survival duration was calculated using Kaplan-Meier curves. Hazard ratio (HR) and $95 \%$ confidence interval (CI) were determined by univariate analyses with log-rank tests. Odds ratio (OR) and $95 \% \mathrm{CI}$ were calculated using multivariate analyses of Cox regression models. Statistical significance was set at $\mathrm{p}<0.05$.

\section{Results \\ Demographics of patients}

According to the inclusion criteria, 436 patients with advanced NSCLC undergoing 4-6 cycles of chemotherapy were initially investigated, then 278 were excluded (PD after first-line chemotherapy, $n=152$; concurrent radiotherapy, $n=95$ and severe complications after chemotherapy, including bone marrow suppression, hepatic and renal insufficiency, $n=31$ ). We finally analyzed data from 158 patients, among whom 71 (34 IIIB and 37 IV stage) underwent MT and 87 (47 IIIB and 40 IV stage) did not.

Table 1 shows that the two groups did not significantly differ in terms of sex, age, marital status, smoking status, type of medical insurance, pathological type, clinical stage, metastatic sites, number of metastatic sites, PS score, first-line chemotherapy drugs, antiangiogenic drugs, or therapeutic efficacy after first-line chemotherapy $(P>0.05)$. Tumor responses evaluated by RECIST v1.1 were similar after first-line chemotherapy, which resulted in $8.1 \% \mathrm{CR}, 33.3 \% \mathrm{PR}$, and $58.6 \% \mathrm{SD}$ in the MT group and $7.0 \% \mathrm{CR}, 33.8 \% \mathrm{PR}$, and $59.2 \% \mathrm{SD}$ in the nonMT group, respectively.

\section{Maintenance therapy prolonged PFS}

The median PFS was 5.6 and 2.8 months in the MT and non-MT groups, respectively (Fig. 1). Therefore, MT prolonged PFS compared with clinical observation alone (HR, 7.657; 95\%CI, 5.083, 11.54; $\chi^{2}, 94.81, P<0.0001$ ).

Among the 71 patients who received MT, the median PFS was 5.1 and 8.2 months for 52 and 19 patients who respectively underwent MT with monotherapy and targeted drugs. The latter was significantly more effective in terms of PFS (HR, 8.327; 95\%CI, 4.580, 15.14; $\chi^{2}$, 48.30; $P<0.0001$; Fig. 2A). The median PFS of 42 and 29 patients with adenocarcinoma and squamous NSCLC, respectively, was 5.85 and 4.3 months, which was not significantly different (HR, 1.399; 95\%CI, 0.8087, 2.419; $\chi^{2}$, 1.440; $P=0.230$; Fig. $2 \mathrm{~B})$. 
Table 1 Demographic comparison of patients in non-MT group and MT group

\begin{tabular}{|c|c|c|c|c|}
\hline Index & Non-MT group $(n=87)$ & MT group $(n=71)$ & $t / x^{2}$ & $P$ value \\
\hline Age (Year, $\bar{x} \pm s)$ & $60.28 \pm 7.78$ & $61.63 \pm 9.30$ & 0.869 & 0.386 \\
\hline Gender $(N)$ & & & 0.079 & 0.778 \\
\hline Man & $52(59.8 \%)$ & $44(62.0 \%)$ & & \\
\hline Woman & $35(40.2 \%)$ & $27(38.0 \%)$ & & \\
\hline Marital status $(N)$ & & & 1.348 & 0.246 \\
\hline Married & $76(87.4 \%)$ & $66(93.0 \%)$ & & \\
\hline Non-married & $11(12.6 \%)$ & $5(7.0 \%)$ & & \\
\hline Smoking history & & & 0.799 & 0.372 \\
\hline Yes & $58(66.7 \%)$ & $52(73.2 \%)$ & & \\
\hline No & $29(33.3 \%)$ & $19(26.8 \%)$ & & \\
\hline Medical insurance & & & 2.069 & 0.558 \\
\hline New rural cooperative & $37(42.5 \%)$ & $26(36.6 \%)$ & & \\
\hline Residents & $25(28.7 \%)$ & $21(29.6 \%)$ & & \\
\hline Employees & $16(18.4 \%)$ & $19(26.8 \%)$ & & \\
\hline Self-pay & $9(10.4 \%)$ & $5(7.0 \%)$ & & \\
\hline Pathological type $(N)$ & & & 0.842 & 0.175 \\
\hline Adenocarcinomas & $65(74.7 \%)$ & $46(64.8 \%)$ & & \\
\hline Squamous & $22(25.3 \%)$ & $25(35.2 \%)$ & & \\
\hline Clinical TNM stage $(N)$ & & & 0.589 & 0.443 \\
\hline$\| \mathrm{II}$ & $47(54.0 \%)$ & $34(47.9 \%)$ & & \\
\hline IV & $40(46.0 \%)$ & $37(52.1 \%)$ & & \\
\hline Metastasis site $(N)$ & & & 0.955 & 0.917 \\
\hline Contralateral lung & $31(35.6 \%)$ & $27(38.0 \%)$ & & \\
\hline Liver & $14(16.1 \%)$ & $9(12.7 \%)$ & & \\
\hline Bone & $18(20.7 \%)$ & $13(18.3 \%)$ & & \\
\hline Brain & $17(19.5 \%)$ & $13(18.3 \%)$ & & \\
\hline Others & $8(9.2 \%)$ & $9(12.7 \%)$ & & \\
\hline Distal metastasis $(N)$ & & & 1.313 & 0.252 \\
\hline $1 \sim 2$ & $55(63.2 \%)$ & $48(67.6 \%)$ & & \\
\hline$\geq 3$ & $32(36.8 \%)$ & $23(32.4 \%)$ & & \\
\hline PS score $(N)$ & & & 0.782 & 0.376 \\
\hline $0 \sim 1$ & $62(71.3 \%)$ & $55(77.5 \%)$ & & \\
\hline 2 & $25(28.7 \%)$ & $16(22.5 \%)$ & & \\
\hline First-line chemotherapy drugs $(N)$ & & & 2.155 & 0.707 \\
\hline Vinorelbine + cisplatin/carboplatin & 7 & 6 & & \\
\hline Taxol + cisplatin/carboplatin & 9 & 6 & & \\
\hline Gemcitabine + cisplatin/carboplatin & 26 & 15 & & \\
\hline Docetaxel + cisplatin/carboplatin & 20 & 18 & & \\
\hline Pemetrexed + cisplatin/carboplatin & 25 & 26 & & \\
\hline Antiangiogenic drugs $(N)$ & & & 0.574 & 0.750 \\
\hline Recombinant human vascular endostatin & 8 & 6 & & \\
\hline Bevacizumab & 11 & 12 & & \\
\hline No & 68 & 53 & & \\
\hline Therapeutic efficacy & & & 0.056 & 0.972 \\
\hline$C R$ & $7(8.1 \%)$ & $5(7.0 \%)$ & & \\
\hline PR & $29(33.3 \%)$ & $24(33.8 \%)$ & & \\
\hline SD & $51(58.6 \%)$ & $42(59.2 \%)$ & & \\
\hline
\end{tabular}

$M T$, maintenance treatment; $T N M$, tumor, node, metastasis; $P S$, performance statue; $C R$, complete response; $P R$, partial response; $S D$, stable disease. $P$ value of age was calculated by two-sided $t$-test, and the rest indexes were calculated by two-sided chi-square test 


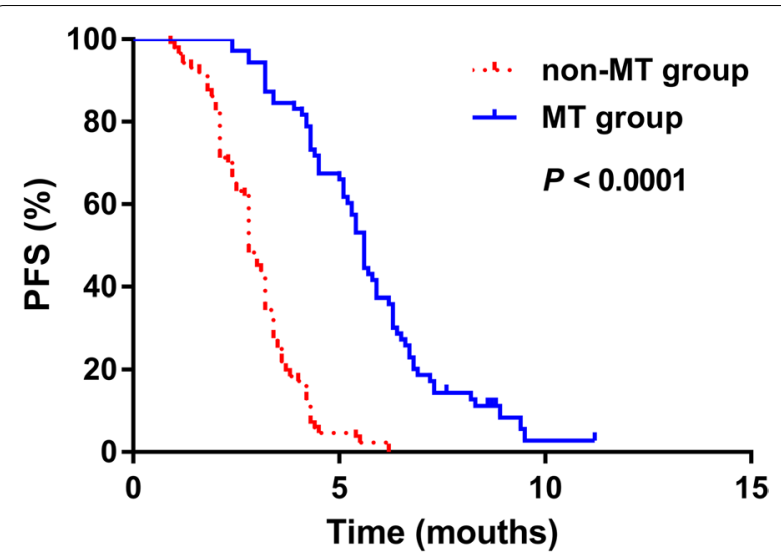

Fig. 1 Comparison of PFS between patients with and without MT. Maintenance therapy extended PFS ( $P<0.0001$, log-rank test). MT, maintenance therapy; PFS, progression-free survival

Of the 49 patients who were maintained with chemotherapy, the median PFS of 18 patients who completed $>4$ cycles was 5.6 months, which was significantly longer than that of 31 patients who completed $<4$ cycles (3.9 months) (HR, 16.18; 95\%CI, 6.295, 37.79; $\chi^{2}, 41.35$; $P<0.0001$; Fig. 3A). The median PFS of 22, 15 , and 15 patients who received MT with pemetrexed, docetaxel, and gemcitabine was $5.6,4.5$, and 4.4 months, respectively (Fig. 3B). However, these results did not reach statistical significance $\left(X^{2}, 2.559 ; P=0.2782\right)$.

Among the 19 patients maintaining with targeted drugs, 13, five, and one received ectinib, erlotinib, and gefitinib, respectively. The median PFS was 6.7 and 9.4 months for five and 14 patients who tolerated treatment for $1-3$ and $\geq 3$ months, respectively, indicating that a longer duration of targeted drug therapy resulted in a better tumor response (HR, 378.3; 95\%CI, 35.79, 3,$999 ; x^{2}=24.34, \mathrm{P}<0.0001$; Fig. 3 C).

\section{Maintenance therapy significantly extended OS}

As of December 31, 2019, 11 and five patients in the MT and non-MT groups remained alive. The OS was significantly longer for 60 eligible patients in the MT group than 82 eligible patients in the non-MT group (14.2 vs. 9.8 months; $\mathrm{HR}=2.856,95 \% \mathrm{CI}$ : $[1.984,4.112] ; \chi^{2}=26.38$, $P<0.0001$; Fig. 4).

Univariate analysis of OS in the MT group showed that pathological type and distant metastasis significantly influenced the clinical outcome of MT $(P=0.041$ and 0.037 , respectively). Thus, patients with adenocarcinoma (HR, 0.31; 95\%CI, 0.20, 0.72) and without distant metastasis (HR, 0.35; 95\% CI, 0.15, 0.60] were more likely to benefit from MT. However, OS did not significantly differ with respect to age (age $\geq 65$ vs. $<65$ years: $p=0.075$ ), sex $(p=0.920)$, smoking history (never vs. formerly: $p=0.912$ ), clinical stage (stage IIIB vs. IV: $p=0.754$ ), and type of medical insurance ( $p=0.658$; Fig. 5$)$.

Multivariate analysis of all eligible patients using Cox regression models showed that sex and MT were independent factors affecting the OS of patients with NSCLC (Table 2). Briefly, the prognosis was worse for men than women, and they had a 1.335-fold higher risk of death than women $(P=0.039)$. MT was a favorable prognostic factor for risk of death, which was 0.412-fold higher than that without MT $(P<0.0001)$.

\section{Adverse events of MT}

The major adverse events of MT were hematological toxicity of leukopenia, neutropenia, thrombocytopenia, and anemia and digestive tract reactions of nausea, vomiting, anorexia, diarrhea, neurotoxicity,
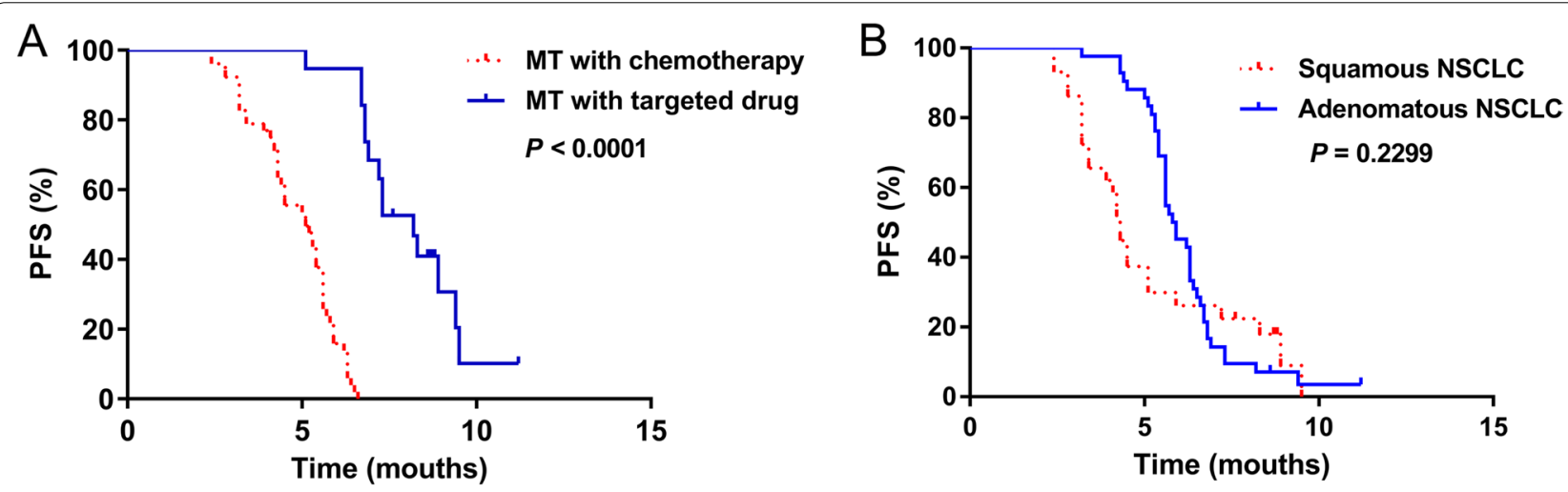

Fig. 2 Progression-free survival. A Patients were maintained with chemotherapy or targeted drugs. Latter elicited more PFS improvement $(P<0.0001$, log-rank tests). B Patients with adenocarcinomas or squamous NSCLC did not significantly differ $(P=0.230$, log-rank tests). MT, maintenance treatment; NSCLC, non-small cell lung cancer; PFS, progression-free survival 


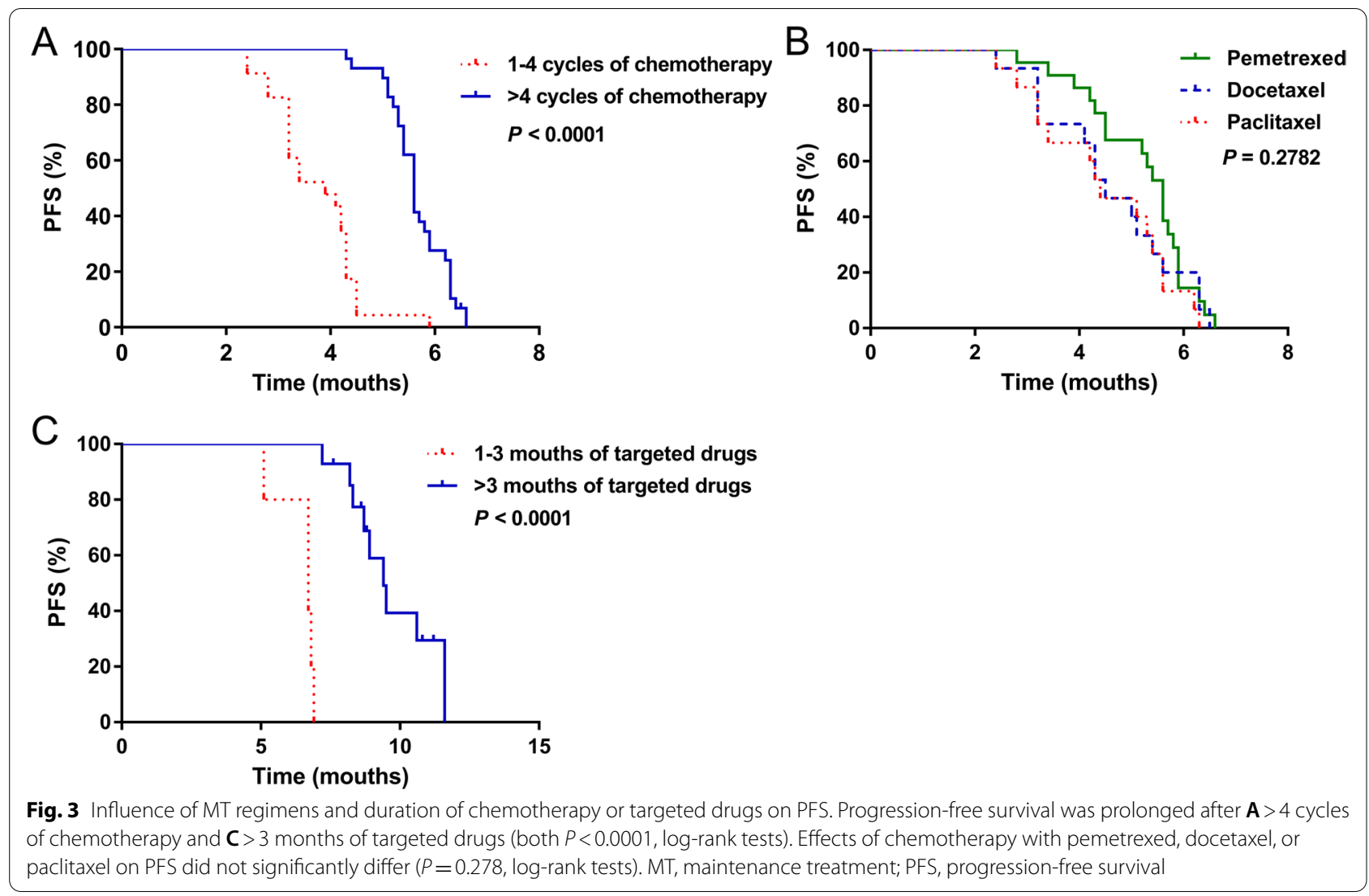

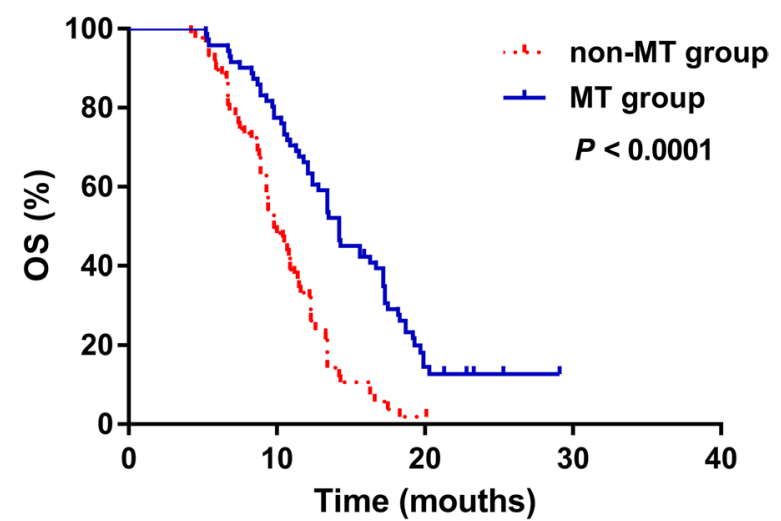

Fig. 4 Comparison of OS between patients with and without MT. Maintenance therapy extended OS ( $P<0.0001$, log-rank tests). MT, maintenance therapy; OS, overall survival

renal toxicity, weakness, myalgia, arrhythmia, elevated transaminase, and rash. Table 3 shows the rates of mild to moderate (grades 1 and 2) or severe (grades 3 and 4 ) adverse events. No serious adverse reactions occurred, and the status of all patients returned to normal after symptomatic treatment.

\section{Discussion}

Patients with stable or responsive NSCLC after 4-6 cycles of first-line chemotherapy do not need treatment before tumor progression [24, 25]. However, NSCLC can progress in such patients during a short period of rest, and rapidly deteriorating disease can negatively affect the likelihood of receiving second-line therapy. Large clinical trials of advanced NSCLC, including ECOG4599 [7], FLEX [26], and others have found that only $50 \%$ of patients given first-line therapy undergo second-line therapy. Thus, MT aimed at controlling NSCLC to prolong PFS has recently attracted attention [27]. Although MT is an innovative strategy for treating NSCLC, it should not be considered as routine therapy for patients who are intolerant or insensitive to previous or additional agents [28]. Some patients decline MT due to economic factors [20]. Consequently, a subset of patients is unable to receive MT (non-MT group). To better understand the application of MT to patients with advanced NSCLC in the real world, we compared the clinical outcomes of PFS and OS between patients with and without MT, to provide a more reliable basis for clinical MT of NSCLC.

This retrospective study found that MT led to better PFS and OS in the real world situation. Furthermore, univariate and multivariate analyses suggested that 


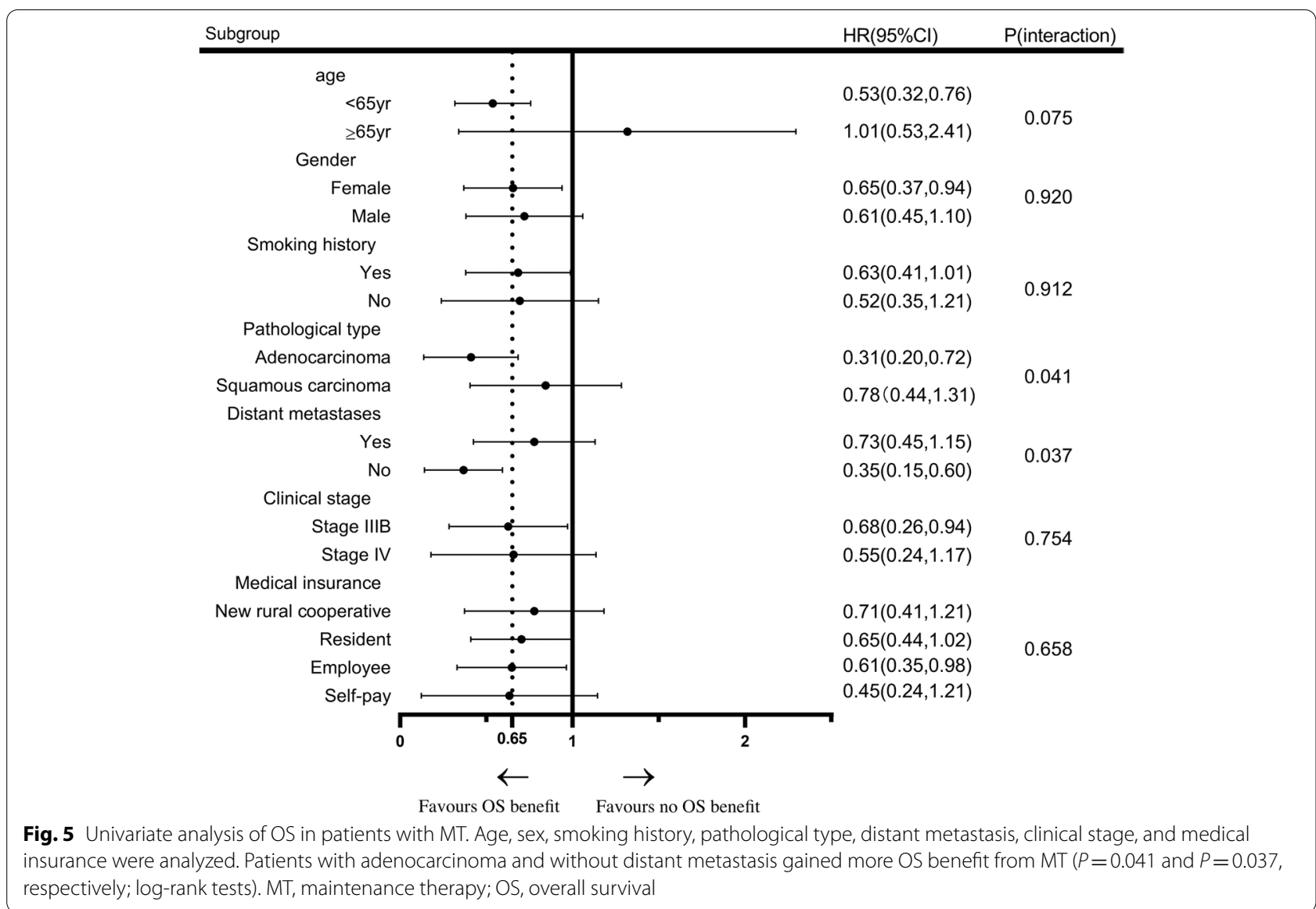

Table 2 Multivariate analysis through Cox regression model for OS in advanced NSCLC patients

\begin{tabular}{|c|c|c|c|c|c|c|}
\hline Variate & Classification & $\begin{array}{l}\text { Regression } \\
\text { coefficient }\end{array}$ & Standard error & $P$ value & Odds ratio & $95 \% \mathrm{Cl}$ \\
\hline Maintenance & Yes/no & -0.854 & 0.238 & $<0.0001$ & 0.412 & $0.22-0.59$ \\
\hline Gender & Woman/man & 0.678 & 0.678 & 0.039 & 1.335 & $1.08-3.84$ \\
\hline Clinical stage & IIIb/IV & 0.732 & 0.732 & 0.065 & 1.886 & $0.97-3.06$ \\
\hline Age & $<65 / \geq 65$ years & 0.398 & 0.398 & 0.078 & 1.248 & $0.78-1.85$ \\
\hline Distant metastasis & No/yes & 0.232 & 0.232 & 0.148 & 1.325 & $0.44-2.12$ \\
\hline Pathological type & Adenocarcinomas/squamous & 0.328 & 0.328 & 0.237 & 1.433 & $0.81-1.97$ \\
\hline Smoking history & No/yes & -0.258 & -0.258 & 0.468 & 0.680 & $0.54-2.38$ \\
\hline
\end{tabular}

$P$ value was calculated by Cox regression model and odds ratio was showed as the ratio of risk of death between the two classifications in each variate

prolonged MT with targeted drugs, adenocarcinoma, and no distant metastasis were potentially favorable characteristics of patients who were likely to benefit from or be appropriate for MT. Female sex and MT were independent prognostic factors for better OS. Collectively, these data provide a reference value for clinical MT of advanced NSCLC.

MT as a potential effective measure to inhibit tumor progression has improved PFS or OS [11, 29]. However, various treatment strategies such as targeted drugs, chemotherapy, immunotherapy, and anti-angiogenic agents might influence different outcomes, [30-32]. Most of our patients who received initial chemotherapy had no driving gene mutations; however, patients who developed gene mutations later might turn to MT with targeted drugs. Classical randomized controlled trials of tyrosine kinase inhibitors (TKIs) against epidermal growth factor receptor (EGFR), including SATURN, INFORM, and 
Table 3 Incidence rate and severity of adverse events in maintenance therapy

\begin{tabular}{lll}
\hline Adverse events & Grade & $\begin{array}{l}\text { Cases } \\
\text { (incidence } \\
\text { rate } \%)\end{array}$ \\
\hline Leukopenia & Grade 1-2 & $27(38.03 \%)$ \\
Neutropenia & Grade 3-4 & $19(26.76 \%)$ \\
Grade 1-2 & $23(32.39 \%)$ \\
Thrombocytopenia & Grade 3-4 & $12(16.90 \%)$ \\
Anemia & Grade 1-2 & $17(23.94 \%)$ \\
Nausea & Grade 3-4 & $7(9.86 \%)$ \\
Vomiting & Grade 1-2 & $31(43.66 \%)$ \\
Diarrhea & Grade 3-4 & $12(16.90 \%)$ \\
Grade 1-2 & $20(28.17 \%)$ \\
Neurotoxicity & Grade 3-4 & $3(4.23 \%)$ \\
Transaminase elevation & Grade 1-2 & $18(25.35 \%)$ \\
Renal toxicity & Grade 3-4 & $2(2.82 \%)$ \\
Wrakness & Grade 1-2 & $7(9.86 \%)$ \\
Grade 3-4 & $2(2.82 \%)$ \\
Grade 1-2 & $4(5.63 \%)$ \\
Grade 3-4 & $1(1.41 \%)$ \\
Grade 1-2 & $13(18.31 \%)$ \\
Grade 3-4 & $2(2.82 \%)$ \\
Grade 1-2 & $9(12.67 \%)$ \\
Grade 3-4 & $3(4.23 \%)$ \\
Grade 1-2 & $33(46.47 \%)$ \\
Grade 3-4 & $5(7.04 \%)$ \\
Grade 1-2 & $9(12.67 \%)$ \\
Grade 3-4 & $3(4.23 \%)$ \\
Grade 1-2 & $3(4.23 \%)$ \\
Grade 1-2 & $2(2.82 \%)$ \\
\hline
\end{tabular}

EORTC008021, as well as a retrospective study, have confirmed that EGFR-TKI is more effective than a placebo [33-36]. The National Comprehensive Cancer Network (NCCN), Cancer Care Ontario (CCO) and Chinese Society Clinical Oncology (CSCO) have proposed advanced biomarker detection for patients with unresectable NSCLC [16, 37, 38]. A recent study found that patients with NSCLC adenocarcinomas gained more benefits on PFS and OS from MT because of the high incidence of driving gene mutations and the access to effective targeted drugs [12]. However, the present study did not find a statistical difference in PFS between adenocarcinomas and squamous NSCLC. This might have been due to the small sample size.

Drug resistance can develop with increasing cycles of chemotherapy [39]. We found that $>4$ cycles of MT with chemotherapy were more effective than fewer cycles, which might differ from initial chemotherapy. This could be explained by the fact that regular and long-term MT with cytotoxic drugs can slowly but persistently control tumor proliferation to provide better tumor responses to treatment, better patient tolerance, and a better quality of life [40]. Pemetrexed, gemcitabine, and docetaxel improve PFS, and pemetrexed can also ameliorate OS [29, 41]; we found little distinction, which again, might have been due to the small sample size.

Although the adverse events of MT were tolerable in the present, as described in previous studies [42, 43], the MT strategy should comprehensively consider the status of the patients, drug resistance, and the prognostic profit in a rational subpopulation $[19,44,45]$. For example, patients with advanced NSCLC often develop distant metastases in the brain accompanied by neurological symptoms, in bone with osteodynia, or the liver with hepatic dysfunction [46]. This could lead to poor compliance and tolerability, thus negating the efficacy of MT. This corresponded with the results of our univariate analysis of OS, which showed that distant metastasis would limit the benefit for patients with NSCLC. Our Cox regression model to predict potential targeted subpopulations of NSCLC identified the independent predictors of female sex and MT, which also reliably confirmed the value of MT for NSCLC.

However, this study retrospectively assessed the clinical efficacy mainly based on imaging data and inpatient medical records, which lacked the double-blind and rigorous nature of a prospective investigation. The small subpopulations restricted the power of comparison, which will need enlarging to ensure the selection of appropriate patients for statistical analysis.

In conclusion, this clinically meaningful retrospective analysis of MT efficacy after first-line chemotherapy for advanced NSCLC provides real-world evidence that supports the survival benefit of MT.

\section{Abbreviations \\ CCO: Cancer Care Ontario; CR: Complete response; CSCO: Chinese Society Clinical Oncology; EGFR: Epidermal growth factor receptor; MT: Maintenance therapy; NSCLC: Non-small cell lung carcinoma; NCCN: National Compre- hensive Cancer Network; OS: Overall survival; PD: Progressive disease; PFS: Progression-free survival; PR: Partial response; RECIST: Evaluation Criteria in Solid Tumors; SD: Stable disease; TKI: Tyrosine kinase inhibitors; UICC: Union for International Cancer Control.}

\section{Acknowledgements}

Not applicable.

\section{Authors' contributions}

$X X, R L$, and YC conceived, designed, and coordinated the study; XX and PZhu participated in the data acquisition. XX, PZha, and $Y L$ analyzed and interpreted the data. $X X, R L$, and JC participated in the study design and statistically analyzed the data. $X X, R L$, and $Y C$ helped draft and revise the manuscript for important intellectual content. All authors read and approved the final manuscript.

\section{Funding}

Not applicable. 


\section{Availability of data and materials}

Not applicable.

\section{Declarations}

\section{Ethics approval and consent to participate}

This study was approved by the Ethics Committee of The First People's Hospital of Yongkang (Approval code: ykyy2018-04).

\section{Consent for publication}

Not applicable.

\section{Competing interests}

The authors declare that they have no competing interests.

\section{Author details}

'Department of Pharmacy, The First People's Hospital of Yongkang, Yongkang 321300, Zhejiang, China. ${ }^{2}$ Department of Pharmacy, People's Hospital of Jinyun, Lishui, Zhejiang 323000, China. ${ }^{3}$ Department of Medical Oncology, The First People's Hospital of Yongkang, No. 599 jinshan West Road, dongcheng Street, Yongkang 321300, Zhejiang, China.

Received: 20 December 2020 Accepted: 19 July 2021

Published online: 06 August 2021

\section{References}

1. Tian Z, Liang C, Zhang Z, Wen H, Feng H, Ma Q, Liu D, Qiang G. Prognostic value of neuron-specific enolase for small cell lung cancer: a systematic review and meta-analysis. World I Surg Oncol. 2020;18:116-116

2. Zhong L, Suo J, Wang Y, Han J, Zhou H, Wei H, Zhu J. Prognosis of limitedstage small cell lung cancer with comprehensive treatment including radical resection. World J Surg Oncol. 2020;18:27-27.

3. Siegel RL, Miller KD, Jemal A. Cancer statistics, 2020. CA Cancer J Clin. 2020;70:7-30

4. Bade BC, Dela Cruz CS. Lung cancer 2020: epidemiology, etiology, and prevention. Clin Chest Med. 2020;41:1-24.

5. Smit HJM, Aerts J, van den Heuvel M, Hiltermann TJN, Bahce I, Smit EF, Dingemans AC, Hendriks LE, Stigt JA, Schramel F, et al. Effects of checkpoint inhibitors in advanced non-small cell lung cancer at population level from the National Immunotherapy Registry. Lung Cancer. 2020:140:107-12.

6. Takashima S, Imai K, Atari M, Matsuo T, Nakayama K, Sato Y, Motoyama S, Shibata H, Nomura K, Minamiya Y. Clinical benefits of adjuvant chemotherapy with carboplatin and gemcitabine in patients with non-small cell lung cancer: a single-center retrospective study. World J Surg Oncol. 2020;18:020-02041.

7. Dahlberg SE, Sandler AB, Brahmer JR, Schiller JH, Johnson DH. Clinical course of advanced non-small-cell lung cancer patients experiencing hypertension during treatment with bevacizumab in combination with carboplatin and paclitaxel on ECOG 4599. J Clin Oncol. 2010:28:949-54.

8. Feng L, Wang Z, Jing L, Zhou Z, Shi S, Deng R, Liu Y, Meng Q. Recombinant human endostatin combined with chemotherapy for advanced squamous cell lung cancer: a meta-analysis. World J Surg Oncol. 2021:19:021-02161.

9. Chen Y, Peng X, Zhou Y, Xia K, Zhuang W. Comparing the benefits of chemoradiotherapy and chemotherapy for resectable stage III A/ N2 non-small cell lung cancer: a meta-analysis. World I Surg Oncol. 2018;16:018-1313.

10. Fujimoto D, Yoshioka H, Kataoka Y, Morimoto T, Kim YH, Tomii K, Ishida T, Hirabayashi M, Hara S, Ishitoko M, et al. Efficacy and safety of nivolumab in previously treated patients with non-small cell lung cancer: a multicenter retrospective cohort study. Lung Cancer. 2018;1 19:14-20.

11. Hu J, Hu J, Liu X, Li L, Bai X. Efficacy and toxicities of combination maintenance therapy in the treatment of advanced non-small-cell lung cancer: an up-to-date meta-analysis. Biosci Rep. 2019:39:BSR20182464.
12. Zhang $L$, Gao $S$, He J. The role of maintenance therapy in the treatment of elderly non-small-cell lung cancer patients: a meta-analysis of randomized controlled trials. Drug Des Devel Ther. 2017;11:3435-40.

13. Soria J-C, Tan DSW, Chiari R, Wu Y-L, Paz-Ares L, Wolf J, Geater SL, Orlov S, Cortinovis D, Yu C-J, et al. First-line ceritinib versus platinum-based chemotherapy in advanced ALK-rearranged non-small-cell lung cancer (ASCEND-4): a randomised, open-label, phase 3 study. Lancet. 2017;389:917-29.

14. Oi F, Hu X, Liu Y, Wang Z, Duan J, Wang J, Dong M. First-line pemetrexedplatinum doublet chemotherapy with or without bevacizumab in non-squamous non-small cell lung cancer: a real-world propensity scorematched study in China. Chin J Cancer Res. 2019;31:749-58.

15. Yoh K, Goto Y, Naito Y, Kishi K, Mori K, Hotta K, Hosomi Y, Yamada K, Tanai C, Tomizawa Y, et al. Impact of maintenance therapy for patients with non-small cell lung cancer in a real-world setting. Anticancer Res. 2017:37:1507-13.

16. Ettinger DS, Wood DE, Aggarwal C, Aisner DL, Akerley W, Bauman JR, Bharat A, Bruno DS, Chang JY, Chirieac LR, et al. NCCN guidelines insights: non-small cell lung cancer, version 1.2020. J Natl Compr Canc Netw. 2019:17:1464-72.

17. Qi J, Guo X, Li A. Doublet vs single-agent maintenance therapy in the treatment of non-small-cell lung cancer: a meta-analysis. Drug Des Devel Ther. 2020;14:2179-85.

18. Spigel DR, Patel JD, Reynolds CH, Garon EB, Hermann RC, Govindan R, Olsen MR, Winfree KB, Chen J, Liu J, et al. Quality of life analyses from the randomized, open-label, phase III PointBreak study of pemetrexed-carboplatin-bevacizumab followed by maintenance pemetrexed-bevacizumab versus paclitaxel-carboplatin-bevacizumab followed by maintenance bevacizumab in patients with stage IIIB or IV nonsquamous non-smallcell lung cancer. J Thorac Oncol. 2015;10:353-9.

19. Tan PS, Bilger M, de Lima LG, Acharyya S, Haaland B. Meta-analysis of firstline therapies with maintenance regimens for advanced non-small-cell lung cancer (NSCLC) in molecularly and clinically selected populations. Cancer Med. 2017;6:1847-60.

20. Xie L, Fan X, Qian B. Maintenance therapy for advanced nonsquamous non-small-cell lung cancer: more questions than answers. J Clin Oncol. 2020;38:769-70.

21. Koul R, Rathod S, Dubey A, Bashir B, Chowdhury A. Comparison of 7th and 8th editions of the UICC/AJCC TNM staging for non-small cell lung cancer in a non-metastatic North American cohort undergoing primary radiation treatment. Lung Cancer. 2018;123:116-20.

22. Schwartz LH, Seymour L, Litière S, Ford R, Gwyther S, Mandrekar S, Shankar L, Bogaerts J, Chen A, Dancey J, et al. RECIST 1.1 - Standardisation and disease-specific adaptations: perspectives from the RECIST Working Group. Eur J Cancer. 2016;62:138-45.

23. Schwartz $L H$, Litière $S$, de Vries E, Ford R, Gwyther S, Mandrekar S, Shankar L, Bogaerts J, Chen A, Dancey J, et al. RECIST 1.1-update and clarification: from the RECIST committee. Eur J Cancer. 2016;62:132-7.

24. Smith IE, O'Brien ME, Talbot DC, Nicolson MC, Mansi JL, Hickish TF, Norton A, Ashley S. Duration of chemotherapy in advanced non-small-cell lung cancer: a randomized trial of three versus six courses of mitomycin vinblastine, and cisplatin. J Clin Oncol. 2001;19:1336-43.

25. Socinski MA, Schell MJ, Peterman A, Bakri K, Yates S, Gitten R, Unger P, Lee J, Lee JH, Tynan M, et al. Phase III trial comparing a defined duration of therapy versus continuous therapy followed by second-line therapy in advanced-stage IIIB/IV non-small-cell lung cancer. J Clin Oncol. 2002:20:1335-43.

26. Pirker R, Pereira JR, Szczesna A, von Pawel J, Krzakowski M, Ramlau R, Vynnychenko I, Park K, Yu CT, Ganul V, et al. Cetuximab plus chemotherapy in patients with advanced non-small-cell lung cancer (FLEX): an open-label randomised phase III trial. Lancet. 2009;373:1525-31.

27. Minami S, Kijima T. Pemetrexed in maintenance treatment of advanced non-squamous non-small-cell lung cancer. Lung Cancer (Auckl). 2015;6:13-25

28. McMullen S, Hess LM, Kim ES, Levy B, Mohamed M, Waterhouse D, Wozniak A, Goring S, Muller K, Muehlenbein C, et al. Treatment decisions for advanced non-squamous non-small cell lung cancer: patient and physician perspectives on maintenance therapy. Patient. 2019;12:223-33.

29. Nishimoto K, Karayama M, Inui N, Yasui H, Hozumi H, Suzuki Y, Furuhashi K, Fujisawa T, Enomoto N, Nakamura Y, et al. Switch maintenance therapy with docetaxel and bevacizumab after induction therapy with cisplatin, 
pemetrexed, and bevacizumab in advanced non-squamous non-small cell lung cancer: a phase II study. Med Oncol. 2018;35:108.

30. MokTS, Wu YL, Ahn MJ, Garassino MC, Kim HR, Ramalingam SS, Shepherd FA, He Y, Akamatsu H, Theelen WS, et al. Osimertinib or platinum-pemetrexed in EGFR T790M-positive lung cancer. N Engl J Med. 2017;376:629-40.

31. Garon EB, Ciuleanu TE, Arrieta O, Prabhash K, Syrigos KN, Goksel T, Park K, Gorbunova V, Kowalyszyn RD, Pikiel J, et al. Ramucirumab plus docetaxel versus placebo plus docetaxel for second-line treatment of stage IV non-small-cell lung cancer after disease progression on platinum-based therapy (REVEL): a multicentre, double-blind, randomised phase 3 trial. Lancet. 2014;384:665-73.

32. Socinski MA, Jotte RM, Cappuzzo F, Orlandi F, Stroyakovskiy D, Nogami N, Rodríguez-Abreu D, Moro-Sibilot D, Thomas CA, Barlesi F, et al. Atezolizumab for first-line treatment of metastatic nonsquamous NSCLC. N Engl J Med. 2018;378:2288-301.

33. Cappuzzo F, Ciuleanu T, Stelmakh L, Cicenas S, Szczésna A, Juhász E, Esteban E, Molinier O, Brugger W, Melezínek I, et al. Erlotinib as maintenance treatment in advanced non-small-cell lung cancer: a multicentre, randomised, placebo-controlled phase 3 study. Lancet Oncol. 2010;11:521-9.

34. Faehling M, Achenbach J, Staib P, Steffen U, Tessen HW, Gaillard VE, Brugger W. Erlotinib in routine clinical practice for first-line maintenance therapy in patients with advanced non-small cell lung cancer (NSCLC). J Cancer Res Clin Oncol. 2018;144:1375-83.

35. Yang YP, Ma YX, Huang Y, Zhao YY, Fang WF, Hong SD, Tian Y, Xue C, Sheng J, Zhang L. QoL analyses from INFORM study, a phase III study of gefitinib versus placebo as maintenance therapy in advanced NSCLC. Sci Rep. 2015;5:11934

36. Gaafar RM, Surmont VF, Scagliotti GV, Van Klaveren RJ, Papamichael D, Welch JJ, Hasan B, Torri V, van Meerbeeck JP. A double-blind, randomised, placebo-controlled phase III intergroup study of gefitinib in patients with advanced NSCLC, non-progressing after first line platinum-based chemotherapy (EORTC 08021/ILCP 01/03). Eur J Cancer. 2011;47:2331-40.

37. Melosky B, Banerji S, Blais N, Chu Q, Juergens R, Leighl NB, Liu G, Cheema P. Canadian consensus: a new systemic treatment algorithm for advanced EGFR-mutated non-small-cell lung cancer. Curr Oncol. 2020;27:e146-55.

38. Hanna NH, Schneider BJ, Temin S, Baker S Jr, Brahmer J, Ellis PM, Gaspar LE, Haddad RY, Hesketh PJ, Jain D, et al. Therapy for stage IV non-small-cell lung cancer without driver alterations: $\mathrm{ASCO}$ and $\mathrm{OH}$ (CCO) joint guideline update. J Clin Oncol. 2020;38:1608-32.
39. Hirano S, Naka G, Takeda Y, likura M, Hayama N, Yanagisawa A, Amano H, Nakamura M, Nakamura S, Tabeta H, Sugiyama H. A prospective, multicenter phase II trial of low-dose erlotinib as maintenance treatment after platinum doublet chemotherapy for advanced non-small cell lung cancer harboring EGFR mutation. Chin Clin Oncol. 2016;5:77.

40. Ellis LM, Bernstein DS, Voest EE, Berlin JD, Sargent D, Cortazar P, GarrettMayer E, Herbst RS, Lilenbaum RC, Sima C, et al. American Society of Clinical Oncology perspective: Raising the bar for clinical trials by defining clinically meaningful outcomes. J Clin Oncol. 2014;32:1277-80.

41. Brodowicz T, Krzakowski M, Zwitter M, Tzekova V, Ramlau R, Ghilezan N, Ciuleanu T, Cucevic B, Gyurkovits K, Ulsperger E, et al. Cisplatin and gemcitabine first-line chemotherapy followed by maintenance gemcitabine or best supportive care in advanced non-small cell lung cancer: a phase III trial. Lung Cancer. 2006;52:155-63.

42. Minami S, Kijima T, Shiroyama T, Okafuji K, Hirashima T, Uchida J, Imamura F, Osaki T, Nakatani T, Ogata Y, et al. Randomized Phase II trial of paclitaxel and carboplatin followed by gemcitabine switch-maintenance therapy versus gemcitabine and carboplatin followed by gemcitabine continuation-maintenance therapy in previously untreated advanced non-small cell lung cancer. BMC Res Notes. 2013;6:3.

43. Yokoi T, Minami S, Shiroyama T, Koba T, Torii Y, Sugimoto H, Niki M, Mori M, Morimura O, Hirashima T, et al. A Phase II Study of Tailored-dose S-1 Plus Carboplatin Followed by Maintenance S-1 for Advanced Squamous Cell Lung Cancer: OSAKA-LCSG 1102. Intern Med. 2019;58:1405-10.

44. Cao X, Tang D, Ratto B, Poole A, Ravichandran S, Jin L, Gao W, Swallow E, Vogelzang NJ. Real-world clinical outcomes of pazopanib immediately after discontinuation of immunotherapy for advanced renal cell carcinoma. Clin Genitourin Cancer. 2020;18:e37-45.

45. Blais N, Kassouf E. Maintenance therapies for non-small cell lung cancer. Front Oncol. 2014;4:213.

46. Gu Y, Zhang J, Zhou Z, Liu D, Zhu H, Wen J, Xu X, Chen T, Fan M. Metastasis patterns and prognosis of octogenarians with NSCLC: a populationbased study. Aging Dis. 2020;11:82-92.

\section{Publisher's Note}

Springer Nature remains neutral with regard to jurisdictional claims in published maps and institutional affiliations.
Ready to submit your research? Choose BMC and benefit from:

- fast, convenient online submission

- thorough peer review by experienced researchers in your field

- rapid publication on acceptance

- support for research data, including large and complex data types

- gold Open Access which fosters wider collaboration and increased citations

- maximum visibility for your research: over 100M website views per year

At BMC, research is always in progress.

Learn more biomedcentral.com/submissions 